\title{
AS INFLUÊNCIAS DO SISTEMA DE ACREDITAÇÃO DE CURSOS UNIVERSITÁRIOS DO MERCOSUL NO MARCO NORMATIVO BRASILEIRO
}

\author{
LAS INFLUENCIAS DEL SISTEMA DE ACREDITACIÓN DE CURSOS \\ UNIVERSITARIOS DEL MERCOSUR EN EL MARCO NORMATIVO BRASILEÑO
}

THE INFLUENCES OF THE ACCREDITATION SYSTEM OF MERCOSUR UNIVERSITY COURSES IN THE BRAZILIAN NORMATIVE FRAMEWORK

\author{
Giselle Cristina Martins REAL ${ }^{1}$ \\ Ana Lúcia MARRAN ${ }^{2}$ \\ Marianne Pereira de SOUZA ${ }^{3}$
}

RESUMO: O trabalho objetiva explicitar como e quando o marco normativo brasileiro recebe e exerce influências das políticas regionais, especificamente do sistema de acreditação do Mercosul em seus processos de revalidação de títulos estrangeiros. Os procedimentos metodológicos adotados foram o levantamento bibliográfico e a pesquisa documental. Os resultados explicitam que a política regional está influenciando a política brasileira de revalidação de títulos, que vem se apoiando no poder indutor da avaliação de cursos (acreditação) como mecanismo de gerar qualidade. E, quando se trata da revalidação de títulos, pode-se afirmar que o Brasil recebeu mais influências das políticas regionais do que as influenciou, apesar de sua tradição, entre os países do bloco, em avaliar a qualidade da educação superior.

PALAVRAS-CHAVE: Educação Superior. Avaliação educacional. Arcu-Sul. Revalidação de títulos.

RESUMEN: El trabajo objetiva explicitar cómo y cuándo el marco normativo brasileño recibe y ejerce influencias de las políticas regionales, específicamente del sistema de acreditación del Mercosur en sus procesos de revalidación de títulos extranjeros. Los procedimientos metodológicos adoptados fueron el levantamiento bibliográfico y la investigación documental. Los resultados explicitan que la política regional está influenciando la política brasileña de revalidación de títulos, que viene apoyándose en el poder inductor de la evaluación de cursos (acreditación) como mecanismo de generar calidad. Y, cuando se trata de la revalidación de títulos, se puede afirmar que Brasil recibió más influencias de las políticas regionales de las que las influenció, a pesar de su tradición, entre los países del bloque, en evaluar la calidad de la educación superior.

${ }^{1}$ Universidade Federal da Grande Dourados (UFGD), Dourados - MS - Brasil. Docente do Programa de PósGraduação em Educação da UFGD. Doutora em Educação pela USP. ORCID: http://orcid.org/0000-000288554141. E-mail: gisellereal@ufgd.edu.br.

${ }^{2}$ Universidade Estadual de Mato Grosso do Sul (UEMS), Dourados - MS - Brasil. Docente do curso de enfermagem. Doutora em Educação pela UFGD. ORCID: http://orcid.org/0000-00017123-9201. E-mail: anamarran1@hotmail.com

${ }^{3}$ Universidade Estadual de Mato Grosso do Sul (UEMS), Dourados - MS - Brasil. Técnica de Nível Superior do Núcleo de Ciências Humanas. Doutora em Educação pela UFGD. ORCID: https://orcid.org/0000-0002-55028073. E-mail: mariannesouza@uems.br 
PALABRAS CLAVE: Educación Universitaria. Evaluación educativa. Arcu-Sur. Revalidación de títulos.

ABSTRACT: This paper aims to explain how and when the Brazilian normative framework receives and exerts influence of regional policies, specifically of the Mercosur accreditation system in its revalidation processes of foreign university titles. The methodological procedures adopted were the bibliographical survey and the documentary research. The results explain that the regional policy is influencing the Brazilian policy of revalidation of titles, which has been supported by the inducing power of course evaluation (accreditation) as a mechanism to generate quality. And when it comes to the revalidation of titles, it can be affirmed that Brazil received more influences from regional policies than it influenced them, despite its tradition among the countries of the bloc to evaluate the quality of higher education.

KEYWORDS: Higher Education. Evaluation educational. Arcu-Sur System. Revalidation of university titles.

\section{Introdução}

O contexto internacional, especialmente quanto aos aspectos político-econômicos, traz influências ao sistema educacional brasileiro, sobretudo à educação superior, considerando as características da globalização em curso (ROBERTSON, 2009). Entre as características da globalização pode-se mencionar a organização dos países sob a forma de blocos econômicos, que engendraram as chamadas políticas regionais.

Ainda que esse fato esteja divulgado na literatura (BALL, 2001; DALE, 2004; JESSOP, 1998), a discussão proposta neste artigo é importante porque situa essas influências, especificamente, no marco normativo brasileiro.

Vale notar que o Brasil, a partir da sua adesão ao Mercosul, em 1992, adotou um conjunto de normas, programas e legislação, envolvendo tanto o Poder Executivo quanto o Poder Legislativo, que altera as proposições usualmente utilizadas até a década de 1990 no que se refere às ações que envolvem a integração entre os países que compõem esse bloco. Para exemplificar esse fato, tomam-se os processos de reconhecimento e de revalidação ${ }^{4}$ de títulos estrangeiros que tiveram suas lógicas processuais transformadas após a promulgação, em 1996, da Lei de Diretrizes e Bases da Educação Nacional (LDB), desencadeadas por instrumentos como o Decreto Federal no. 5.518/2005, entre outras medidas (CONCEIÇÃO, 2013).

${ }^{4}$ No contexto brasileiro, o termo utilizado para o processo de reconhecimento de títulos estrangeiros de graduação é revalidação. 
Portanto, este artigo refere-se à política regional, que traz em seu bojo a complexidade da rede de relações que envolvem as influências múltiplas entre países do eixo sul-sul e do eixo sul-norte, bem como as diretrizes regionais aos Estados-Nação e as interferências interregionais, tendo como base o marco normativo educacional brasileiro quanto aos processos de revalidação de títulos estrangeiros.

Nesse sentido, partindo do pressuposto de que o Brasil, ao ser membro integrante do Mercosul Educacional, influencia as políticas regionais ao mesmo tempo em que seria influenciado por elas (DALE, 2004), e que, ainda, o próprio Setor Educacional do Mercosul (SEM) partilharia interferências inter-regionais (ROBERTSON, 2009), pergunta-se: como e quando o marco normativo brasileiro recebe e exerce influências das políticas regionais, especificamente do sistema de avaliação do Mercosul, identificado como acreditação de cursos, em seus processos de revalidação de títulos estrangeiros?

Embora a legislação educacional brasileira não adote o termo acreditação, que é conceito próprio dos países latino-americanos, inclusive dos países que compõem o Mercosul, o termo passa a ser utilizado, no Brasil, por força das políticas regionais com o sentido de avaliação da qualidade. Cumpre destacar que o termo acreditação de cursos agrega em um único conceito os processos de avaliação e de regulação de cursos, enquanto, no Brasil, esses processos são distintos, embora estejam relacionados. Nesse sentido, o site oficial do Ministério da Educação (MEC) utilizando o termo informa que:

[...] a intenção é que a acreditação funcione como um aliado no processo de revalidação de diplomas. No entanto, a revalidação não seria feita de forma automática, já que os coordenadores acordaram que os países do Mercosul ainda precisam fortalecer as suas avaliações internamente. O sistema respeita as legislações de cada país e a autonomia das instituições universitárias (MEC, 2019).

Portanto, pode-se observar que há a intencionalidade de que os processos de avaliação regional, identificados como acreditação de cursos, referenciem as políticas de revalidação de títulos no Brasil, o que justifica a relevância de pesquisas que analisem esse processo.

Assim, para responder ao problema de pesquisa levantado, adotou-se como procedimentos metodológicos: i) levantamento bibliográfico, tendo como principal fonte de pesquisa dissertações e teses sobre o tema, considerando que as produções sob a forma de artigos, embora acatadas, são incipientes, ainda; ii) pesquisa documental, tendo como parâmetro o conjunto de normas referentes ao sistema de avaliação do Mercosul e do próprio Brasil, tendo como fontes os documentos e normas oficiais, localizadas nos sites das agências responsáveis pela avaliação em cada um desses sistemas. 
Os resultados foram organizados em duas seções e mais as considerações finais. Uma seção trata do papel do Sistema de Acreditação de Cursos Universitários do Mercosul (ArcuSul) na construção da política regional de avaliação de cursos e a outra seção foca a transformação da política de revalidação de títulos estrangeiros no Brasil, a partir da análise do processo de construção de seu marco normativo.

\section{A política regional de acreditação de cursos e o papel do Arcu-Sul}

O incremento de políticas de acreditação caracteriza as ações do Mercosul para a educação superior, desde a constituição, nos anos 1990, do Setor Educacional, cuja criação teve como ponto de partida o entendimento, pelos ministros de Educação dos Estados-membros do bloco, do papel estratégico da educação no processo de integração regional.

Nesse contexto, para viabilizar o reconhecimento de títulos nos países da região, a acreditação de cursos de graduação é a temática com maiores avanços no Setor Educacional (KRAWCZYK; SANDOVAL, 2012; REAL, 2015) e figura dentre os objetivos e/ou metas previstos nos planos de ação aprovados pelo SEM, bem como nos demais documentos do Mercosul, dentre os quais o Plano de Ação do Estatuto da Cidadania, aprovado em 2010.

Elaborado a partir dos resultados do Mecanismo Experimental de Acreditação de Cursos para o Reconhecimento de Títulos de Graduação Universitária nos Países do Mercosul (Mexa), o Sistema Arcu-Sul foi instituído em 2008, com a assinatura do Acordo nº ${ }^{\circ}$ 17/2008, pelos ministros da educação dos Estados Parte Argentina, Brasil, Paraguai, Uruguai, e dos Estados Associados Bolívia e Chile.

O Acordo $\mathrm{n}^{\circ}$. 17/2008 reafirma o foco da política regional na mobilidade e na qualidade, uma vez que a acreditação é resultado da avaliação que certifica " [...] a qualidade acadêmica dos cursos de graduação estabelecendo que satisfazem o perfil do graduado e os critérios de qualidade previamente aprovados no âmbito regional para cada diploma” (MERCOSUL, 2008, p. 3).

Assim, os ministros consideram a avaliação como um instrumento para se atingir a qualidade necessária para o reconhecimento de títulos e, consequentemente, para a promoção do desenvolvimento econômico, social, político e cultural dos países da região. Desse modo, o Sistema deve oferecer garantia pública na região do nível acadêmico e científico dos cursos, estabelecido conforme critérios e perfis tanto ou mais exigentes que os aplicados pelos países em seus âmbitos nacionais análogos (MERCOSUL, 2008). Essas informações evidenciam a 
complexidade do sistema regional, que deverá garantir que os cursos acreditados terão qualidade acima da qualidade dos países do Mercosul.

Percebe-se que, diante da importância econômica dos diplomas, o Arcu-Sul foi instituído com objetivo de vincular a acreditação de cursos com a regulação (SOUZA, 2018), uma vez que a qualidade regional, determinada pela avaliação, deve fundamentar as decisões dos países do Mercosul acerca do reconhecimento de títulos.

Destaca-se que a acreditação regional é realizada por meio da avaliação externa e da autoavaliação, e é coordenada pela Rede de Agências Nacionais de Acreditação (Rana), cuja composição consta no quadro 1 .

Quadro 1 - Relação das agências nacionais de acreditação integrantes da Rana (2019)

\begin{tabular}{|c|c|}
\hline País & Agência Nacional de Acreditação \\
\hline Argentina & Comissão Nacional de Avaliação e Acreditação \\
\hline Bolívia & Comissão Nacional de Acreditação de Carreiras Universitárias \\
\hline Brasil & $\begin{array}{r}\text { Instituto Nacional de Estudos e Pesquisas Anísio Teixeira } \\
\text { Comissão Nacional de Avaliação da Educação Superior } \\
\text { Secretaria de Regulação e Supervisão da Educação Superior }\end{array}$ \\
\hline Chile & Comissão Nacional de Acreditação \\
\hline Colômbia & Conselho Nacional de Acreditação \\
\hline Paraguai & Agência Nacional de Avaliação e Acreditação Superior \\
\hline Uruguai & Comissão Ad hoc de Acreditação para administrar o ARCU-SUL. \\
\hline
\end{tabular}

Fonte: Elaborado pelas autoras de acordo com dados da página eletrônica do Sistema ARCU-SUL (2019).

Observa-se nos dados do quadro 1 que, além dos países que assinaram o Acordo $\mathrm{n}^{\circ}$. 17/2008, a Colômbia também integra a Rana. Cabe realçar que a Venezuela também participou do primeiro ciclo do Arcu-Sul, que ocorreu no período de 2008 a 2015, contudo, após a sua suspensão do Mercosul (MERCOSUL, 2019), sua agência foi retirada da Rana.

Os dados apontam ainda que, com exceção do Brasil e do Uruguai, os países integrantes do Sistema indicaram para a composição da Rana órgãos destinados especificamente ao processo de acreditação. No caso brasileiro, os órgãos indicados integram o Sistema Nacional de Avaliação da Educação Superior (SINAES), instituído em 2004.

No primeiro ciclo do Arcu-Sul foram acreditados 246 cursos de graduação, dos quais 78 são oriundos do Brasil, ou seja, mais de trinta por cento dos cursos são brasileiros. Isso mostra que, embora não possua uma agência específica para a acreditação, o sistema brasileiro 
utilizou a sua experiência em avaliação para implementar o Sistema regional e foi o país que acreditou a maior quantidade de cursos.

Desse modo, os resultados do primeiro ciclo permitem inferir que o Brasil teria uma melhor qualidade de curso atestada pela avaliação regional. Essa constatação, somada a questões como os procedimentos avaliativos adotados pelo Sistema, que não contemplam o desempenho dos estudantes, promoveram resistências no Brasil quanto à promoção do reconhecimento de títulos a partir da acreditação regional (VERHINE; FREITAS, 2012).

Nota-se que a implementação do Arcu-Sul é permeada por processos de tensão quanto à vinculação dos resultados do Sistema ao reconhecimento de títulos. Todavia, os resultados do primeiro ciclo mostram que as estratégias utilizadas pelo SEM foram eficientes, considerando a quantidade de países participantes e de cursos acreditados e, especialmente, as influências nas políticas educacionais dos países integrantes do Mercosul, que passaram a adotar políticas de acreditação e a alterar suas políticas de reconhecimento de títulos.

Pode-se afirmar que o discurso da qualidade foi utilizado pela política regional para induzir os países do Mercosul a adotarem o Arcu-Sul como política de Estado (SOUZA, 2018). Entretanto, entende-se que a qualidade ficou secundarizada diante da finalidade do Sistema, que é o reconhecimento de títulos nos países da América do Sul.

Essas influências foram intensificadas, a partir de 2010, com as ações do Grupo de Trabalho Reconhecimento de Títulos (GT-RT), constituído por representantes dos Estados Parte do Mercosul para articular os resultados do Arcu-Sul com o reconhecimento de títulos. Após oito anos de discussões, em novembro de 2018, a proposta de Acordo sobre o reconhecimento de títulos de graduação (MERCOSUL, 2018) foi aprovada pelos ministros de educação.

Assim, os resultados do Sistema regional serão utilizados como parâmetro para o reconhecimento de títulos nos sistemas nacionais, inclusive no Brasil. As influências do Mercosul no sistema brasileiro são explicitas na próxima seção, que focaliza as transformações da política nacional de revalidação.

\section{A construção do marco normativo brasileiro para a revalidação de títulos estrangeiros}

A revalidação de diplomas estrangeiros tem sido foco de ações do Estado brasileiro com maior intensidade após o engendramento das políticas educacionais do Mercosul, tendo em vista a migração de estudantes brasileiros na faixa de fronteira, o aumento da demanda de 
diplomas a serem revalidados, a participação do Brasil nos espaços do Mercosul e as normatizações publicadas pelo $\mathrm{CNE}$, o que mostra a influência do contexto internacional no local.

Esta seção dedica-se a apresentar e a problematizar como a revalidação de diplomas se mantém no arcabouço jurídico nacional representado por leis, decretos, resoluções e portarias, as características e mudanças ocorridas nessas legislações, publicadas desde 1961. O quadro 2 expõe as legislações brasileiras sobre revalidação de títulos de graduação publicadas no período de 1961 a 1995.

Quadro 2 - Legislações sobre revalidação de títulos de graduação no Brasil, publicadas entre 1961 a 1995

\begin{tabular}{|l|l|l|}
\hline \multicolumn{1}{|c|}{ Legislação } & \multicolumn{1}{|c|}{ Especificação } & \multicolumn{1}{c|}{ Especificidade } \\
\hline $\begin{array}{l}\text { Lei } \\
4024 / 1961\end{array}$ & $\begin{array}{l}\text { Fixa as Diretrizes e Bases da Educação } \\
\text { Nacional. Art. 103 trata da revalidação de } \\
\text { diplomas estrangeiros. }\end{array}$ & $\begin{array}{l}\text { Diplomas estrangeiros necessitam de } \\
\text { revalidação, exceto os emitidos por } \\
\text { países que têm convênio cultural com } \\
\text { o Brasil. }\end{array}$ \\
\hline $\begin{array}{l}\text { Lei no. 5540/ } \\
1968\end{array}$ & $\begin{array}{l}\text { Fixa normas de organização e } \\
\text { funcionamento do ensino superior e sua } \\
\text { articulação com a escola média, e dá outras } \\
\text { providências. Art. 51 aborda a revalidação } \\
\text { de diplomas estrangeiros. }\end{array}$ & $\begin{array}{l}\text { OConselho federal de educação fixará } \\
\text { condições para a revalidação de } \\
\text { diplomas estrangeiros. }\end{array}$ \\
\hline $\begin{array}{l}\text { Portaria CFE } \mathrm{n}^{\circ} . \\
23 / 1971\end{array}$ & $\begin{array}{l}\text { O Conselho Federal de Educação fixa as } \\
\text { condições para revalidação de diplomas } \\
\text { estrangeiros. }\end{array}$ & $\begin{array}{l}\text { Os diplomas estrangeiros devem ser } \\
\text { revalidados por universidades } \\
\text { públicas ou privadas e, se for o caso, } \\
\text { deve-se apurar a capacidade } \\
\text { profissional do portador. }\end{array}$ \\
\hline $\begin{array}{l}\text { Resolução CFE } \\
\mathrm{n}^{\circ} .43 / 1975\end{array}$ & $\begin{array}{l}\text { Fixa normas para revalidação de diplomas e } \\
\text { certificados de cursos de Graduados, } \\
\text { expedidos por estabelecimentos } \\
\text { estrangeiros de ensino superior. }\end{array}$ & $\begin{array}{l}\text { A revalidação deve ser feita por } \\
\text { universidade pública com curso } \\
\text { correspondente ao realizado no } \\
\text { exterior e deve-se verificar a } \\
\text { necessidade do profissional no Brasil. }\end{array}$ \\
\hline $\begin{array}{l}\text { Resolução CFE } \\
\mathrm{n}^{\circ} .3 / 1985\end{array}$ & $\begin{array}{l}\text { Dispõe sobre a revalidação de diplomas e } \\
\text { certificados de cursos de graduação e pós- } \\
\text { graduação expedidos por estabelecimentos } \\
\text { estrangeiros de ensino superior. }\end{array}$ & $\begin{array}{l}\text { A revalidação pode ser feita por } \\
\text { universidades públicas ou privadas e } \\
\text { institutos federais de ensino superior. } \\
\text { Mantém-se a obrigatoriedade do } \\
\text { registro do diploma junto ao MEC, } \\
\text { mesmo que exista acordo cultural } \\
\text { entre o Brasil e o país de origem } \\
\text { dispensando a revalidação. Não está } \\
\text { prevista a verificação da necessidade } \\
\text { da profissão no Brasil. }\end{array}$ \\
\hline
\end{tabular}

Fonte: Marran (2018)

A revalidação de diplomas estrangeiros está presente nas Leis de Diretrizes e Bases da Educação desde 1961, quando foi publicada a primeira LDB, na qual é possível notar que a preocupação se restringe à chancela, à conferência de que aquele diploma era verdadeiro. Com a reforma universitária em 1968, é explicitado o envolvimento das universidades brasileiras 
nesse processo e anunciado que o CFE fixará as condições para revalidação de diplomas estrangeiros, o que é feito com a publicação de uma Portaria em 1971.

Nesse documento tanto as universidades oficiais (públicas) quanto as universidades privadas poderiam realizar o processo de revalidação. Para que o diploma fosse revalidado era preciso que o curso realizado no exterior tivesse equivalência com o ofertado no Brasil. Para isso se contava com análise documental e, se necessário, provas teóricas e práticas. Cabe destacar que esse é o primeiro documento que traz orientações mais detalhadas sobre o processo de revalidação, e é a partir dele que as demais resoluções e portarias sobre o assunto são construídas.

Nota-se nos dados do quadro 2 que, no decorrer de 24 anos, há a publicação de cinco documentos que abordam a revalidação de diplomas de graduação e, considerando que de 1985 a 1995 nenhum outro documento acerca do tema foi publicado, se pode considerar 34 anos. Atenta-se, ainda, que a preocupação com a verificação da equivalência do ensino realizado no exterior com o ofertado no Brasil remete à reflexão acerca do controle do Estado sobre o perfil profissional desejado do trabalhador no país. Independente da aquisição do conhecimento adquirido no exterior, esse deveria atender ao interesse nacional. O foco de análise estava centrado no contexto interno.

No ano de 1992 foi criado o Mercosul. Nesse período, o Brasil vivia o processo de redemocratização e de abertura das fronteiras, que estabeleceram um novo cenário no país. O quadro 3 destaca os documentos publicados no Brasil que tratam da revalidação de diplomas após a criação do Mercosul, partindo da LDB, de 1996, até a última legislação publicada, em 2016, a Portaria MEC nº. 22.

Com a elaboração da LDB, publicada em 1996, a revalidação de diplomas estrangeiros manteve-se presente na pauta de discussões. Nesse período estavam se estabelecendo políticas regionais e, diante desse novo cenário internacional, o nacional também mudou.

Quadro 3 - Legislações sobre revalidação de títulos de graduação no Brasil, publicadas entre 1996 e 2016

\begin{tabular}{|l|l|l|}
\hline \multicolumn{1}{|c|}{ Legislação } & \multicolumn{1}{|c|}{ Especificação } & \multicolumn{1}{c|}{ Especificidade } \\
\hline Lei no. 9394/1996 & $\begin{array}{l}\text { Estabelece as diretrizes e bases da } \\
\text { educação nacional. }\end{array}$ & $\begin{array}{l}\text { A revalidação deve ser feita por } \\
\text { universidades públicas, respeitando-se os } \\
\text { acordos internacionais de reciprocidade ou } \\
\text { equiparação. Os diplomas revalidados } \\
\text { também deverão ser por elas registrados. }\end{array}$ \\
\hline $\begin{array}{l}\text { Resolução } \\
\text { CNE/CES }\end{array} \mathrm{n}^{\circ}$. & $\begin{array}{l}\text { Estabelece normas para a revalidação de } \\
\text { diplomas de graduação expedidos por } \\
\text { estabelecimentos estrangeiros de ensino } \\
\text { superior. }\end{array}$ & $\begin{array}{l}\text { Atendimento a LDB } \\
\text { estabelecimento de prazo para a universidade } \\
\text { concluir o processo de revalidação. }\end{array}$ \\
\hline
\end{tabular}




\begin{tabular}{|c|c|c|}
\hline $\begin{array}{ll}\text { Decreto } & \mathrm{n}^{\circ} . \\
5.518 / 2005 & \end{array}$ & $\begin{array}{l}\text { Promulga o Acordo de Admissão de } \\
\text { Títulos e Graus Universitários para o } \\
\text { Exercício de Atividades Acadêmicas nos } \\
\text { Estados Partes do Mercosul. }\end{array}$ & $\begin{array}{l}\text { Facilita o intercâmbio acadêmico entre as } \\
\text { IES da região mercosulina. E a atuação } \\
\text { profissional docente entre essas IES. }\end{array}$ \\
\hline $\begin{array}{l}\text { Resolução } \\
\text { CNE/CES } \\
8 / 2007\end{array}$ & $\begin{array}{l}\text { Altera o art. } 4^{\circ} \text { e revoga o art. } 10 \text { da } \\
\text { Resolução CNE/CES no. 1/2002. }\end{array}$ & $\begin{array}{l}\text { Inclui a obrigatoriedade de período para } \\
\text { protocolar pedido de revalidação; desobriga } \\
\text { as IES estabelecer regras internas para } \\
\text { revalidação. }\end{array}$ \\
\hline $\begin{array}{l}\text { Resolução } \\
\text { CNE/CES } \\
7 / 2009\end{array}$ & $\begin{array}{l}\text { Altera o } \$ 2^{\circ} \text { do art. } 8^{\circ} \text { da Resolução } \\
\text { CNE/CES } n^{\circ} .8 \text {, de } 4 \text { de outubro de } 2007 \text {. }\end{array}$ & $\begin{array}{l}\text { Recursos ao CNE, somente em caso de erro } \\
\text { de fato ou de direito, durante o processo na } \\
\text { IES. }\end{array}$ \\
\hline $\begin{array}{l}\text { Portaria } \\
\text { interministerial } \\
\text { MEC/MS n } \mathrm{n}^{\mathrm{o}} \text {. } \\
865 / 2009\end{array}$ & $\begin{array}{l}\text { Aprova o Projeto Piloto de revalidação } \\
\text { de diploma de médico expedido por } \\
\text { universidades } \\
\text { (REVALIDA). }\end{array}$ & $\begin{array}{l}\text { Projeto que traz a realização de prova escrita } \\
\text { e prática, como uma alternativa, para } \\
\text { revalidação de diplomas médicos. }\end{array}$ \\
\hline $\begin{array}{l}\text { Portaria } \\
\text { interministerial } \\
\text { MEC/MS } \mathrm{n}^{\circ} \text {. } \\
278 / 2011\end{array}$ & $\begin{array}{l}\text { Institui o } \quad \text { Exame Nacional de } \\
\text { Revalidação de Diplomas Médicos } \\
\text { expedidos por universidades estrangeiras } \\
\text { (REVALIDA). }\end{array}$ & $\begin{array}{l}\text { O REVALIDA deixa de ser um projeto e é } \\
\text { instituído como programa, sem sofrer } \\
\text { alterações no que vinha sendo realizado. }\end{array}$ \\
\hline $\begin{array}{l}\text { Resolução } \\
\text { CNE/CES } \\
3 / 2016\end{array}$ & $\begin{array}{l}\text { Dispõe sobre normas referentes à } \\
\text { revalidação de diplomas de cursos de } \\
\text { graduação e ao reconhecimento de } \\
\text { diplomas de pós-graduação stricto sensu } \\
\text { (mestrado e doutorado), expedidos por } \\
\text { estabelecimentos estrangeiros de ensino } \\
\text { superior. }\end{array}$ & $\begin{array}{l}\text { Traz novidades no processo de revalidação: } \\
\text { cria a tramitação simplificada; dispensa } \\
\text { tradução de documentos em inglês, espanhol } \\
\text { e francês e prevê a criação de um sistema } \\
\text { eletrônico para os processos de revalidação } \\
\text { de diplomas estrangeiros. }\end{array}$ \\
\hline $\begin{array}{l}\text { Portaria MEC } n^{\circ} \text {. } \\
22 / 2016\end{array}$ & $\begin{array}{l}\text { Dispõe sobre normas e procedimentos } \\
\text { gerais de tramitação de processos de } \\
\text { solicitação de revalidação de diplomas } \\
\text { de graduação estrangeiros e ao } \\
\text { reconhecimento de diplomas de pós- } \\
\text { graduação stricto sensu (mestrado e } \\
\text { doutorado), expedidos por } \\
\text { estabelecimentos estrangeiros de ensino } \\
\text { superior. }\end{array}$ & $\begin{array}{l}\text { Orienta o processo de revalidação, traz } \\
\text { detalhamentos da tramitação simplificada, } \\
\text { anuncia a Plataforma Carolina Bori. }\end{array}$ \\
\hline
\end{tabular}

Fonte: Elaborado pelas autoras a partir das legislações brasileiras sobre a revalidação de diplomas estrangeiros publicadas no período de 1996 a 2016.

Cabe realçar que os diplomas de graduação voltaram a ser revalidados somente por universidades públicas. Observa-se que, embora se tenha, nesse momento, a participação do Brasil no Mercosul e a constituição de políticas regionais, o texto da LDB de 1996 ainda não traz essas influências. Sua preocupação se mantém em torno da garantia da soberania nacional no que se refere ao controle da entrada de profissionais e de diplomas estrangeiros.

A partir de 2002 vários documentos foram publicados, iniciando pela Resolução CNE/CES nº. 1, que revoga a Resolução nº. 3 de 1985. Contudo, é a Resolução CNE/CES nº. 8, de 2007, que altera o Art. 4 e revoga o Art. 10 da Resolução de 2002, que traz as maiores mudanças com foco na regulação do processo ao determinar etapas a serem realizadas e estabelecer às universidades a fixação de prazos. A revogação do Art.10 explicita o desejo do Estado em regular esse procedimento. 
Em 2009, a Resolução nº 7 definiu que somente caberia recursos à Câmara de Ensino Superior (CES) em caso de erro de fato ou de direito, o que provavelmente ocorreu devido ao grande número de recursos à CES. Nesse sentido, Conceição (2013) afirma que o aumento da demanda interna é o principal motivo da revalidação de diplomas ter adquirido destaque na agenda do Executivo, que passou a publicar novos documentos para regulamentar o processo.

Com o avanço da globalização e, especialmente, com o desenvolvimento das ações do Mercosul, promovendo a circulação de pessoas no espaço regional, aumentou o número de pessoas que pleiteiam formação profissional em outros países e vêm, por exemplo, ao Brasil, com o objetivo de inserção ao mercado de trabalho.

Assim, o Estado age também junto ao Mercosul e, em 1999, o Brasil assinou um acordo que prevê a admissão de títulos para fins de exercício de atividades acadêmicas no âmbito do bloco regional. Esse acordo foi aprovado no Poder Legislativo brasileiro em 2003 e institucionalizado pelo Poder Executivo por meio do Decreto n ${ }^{\circ} .5 .518$, de 2005. O documento facilita o intercâmbio acadêmico entre as IES da região mercosulina, mas versa sobre os portadores de diplomas que obtêm o título em um dos Estados-partes do Mercosul e desejam atuar profissionalmente em outro (MAZUOLLI, 2011).

Ainda em 2009, foi aprovada uma Portaria que deu origem ao programa Revalida. O Projeto Piloto teve início em 2010 e, um ano depois, passou a ser um programa permanente, de acordo com a publicação da Portaria Interministerial $n^{\circ}$. 278/2011, sem alterações do que já vinha sendo realizado. Essa legislação específica para uma categoria profissional é justificada em razão da grande demanda reprimida de diplomas médicos, como apresentado na justificativa da criação do programa.

Para a implementação do programa, houve a adoção de provas e exames para a revalidação de títulos como procedimento exclusivo, e não complementar como nas normatizações anteriores, levando a uma centralização de etapas no processo de revalidação. Em consequência da sua aceitação, em 2015, o Revalida foi apresentado via projeto de lei no Senado Federal e, após aprovação, encontra-se em tramitação na Câmara dos Deputados.

Há também outro projeto de Lei que trata da revalidação de diplomas estrangeiros tramitando no Congresso Nacional. Esse projeto abrange todos os diplomas de graduação e pósgraduação. Trata-se do PL no. 7841/2014, que altera o Art. 48 da LDB/1996. Inicialmente, o documento sugeria a revalidação automática para diplomas com qualidade acadêmica reconhecida, entretanto, após resistência ao termo automática, pelo campo universitário e por parte dos parlamentares, o termo foi substituído por facilitada. 
Esse PL foi apresentado em 2011 no Senado e, após aprovado em 2015, foi encaminhado à Câmara dos Deputados, onde se encontra em tramitação. Em 2011 o Conselho Nacional de Educação (CNE) também se debruçou sobre esse tema e decidiu contribuir com os parlamentares e somar forças para buscar uma solução diante do aumento da demanda de diplomas a serem revalidados.

Em 2016, duas legislações foram publicadas trazendo novas orientações acerca da revalidação de diplomas, a Resolução CNE/CES nº. 03/2016 e a Portaria MEC nº. 22/2016. Cabe destacar que elas contemplam sugestões e demandas que foram discutidas nas audiências públicas promovidas pelo Senado Federal durante a tramitação do PL naquela casa de leis (MARRAN, 2018).

Entre as principais novidades estão a tramitação simplificada para diplomas emitidos por cursos acreditados pelo Arcu-Sul e a Plataforma Carolina Bori, que tornou os processos de revalidação informatizados.

A tramitação simplificada dispensa a análise aprofundada da formação realizada no exterior, restringindo-se à conferência dos documentos apresentados e à veracidade deles, o que torna o processo de revalidação mais rápido e menos burocrático para os cursos acreditados, atendendo uma das demandas do SEM.

Cumpre sublinhar que o SEM trabalhou para a elaboração de um sistema de reconhecimento de títulos que facilitasse o processo e que o governo brasileiro se comprometeu com a criação de um sistema que tornasse a revalidação mais transparente e ágil. Pode-se inferir, então, que a criação do Portal e da Plataforma Carolina Bori seja parte desse Sistema.

Observa-se que as legislações que orientam a revalidação de diplomas estrangeiros foram sofrendo alterações ao longo dos anos, e que após a criação do Mercosul ocorreram mudanças buscando atender o novo cenário.

\section{Considerações Finais}

Diante do fenômeno da globalização em curso que, entre outros fatores, engendrou políticas regionais que exercem e sofrem influências no/do contexto dos Estados-Nação, o presente artigo buscou aprofundar a compreensão presente na literatura da área da Educação sobre as transformações que ocorreram na política de revalidação de títulos, configuradas no marco normativo brasileiro.

Em outras palavras, objetivou-se responder ao seguinte problema: como e quando o marco normativo brasileiro recebe e exerce influências das políticas regionais, especificamente 
do sistema de avaliação do Mercosul, identificado como acreditação de cursos, em seus processos de revalidação de títulos estrangeiros?

Foi possível observar, a partir dos dados levantados, que a política de revalidação de títulos estrangeiros no Brasil é engendrada como princípio normativo a partir de 1961, quando é sancionada a Lei nº .4 .024 , a primeira Lei de Diretrizes e Bases da Educação Nacional. Até os anos de 1990, período que antecede a entrada do Brasil no Mercosul, essa política tinha como foco o contexto interno, ou seja, a preocupação estava em chancelar títulos obtidos no exterior como forma de controle do Estado sobre o perfil profissional desejado do trabalhador no país.

Esse foco passou a ter delineamento exógeno a partir da materialização da Resolução $n^{\circ}$. 1/2002 do CNE, cuja finalidade foi estabelecer normas para a revalidação de diplomas de graduação expedidos por estabelecimentos estrangeiros de ensino superior, disciplinando o processo, apesar da autonomia constitucional prevista para as universidades. O conjunto de normas implementadas após esse período de 41 anos se intensificou, ao mesmo tempo em que foi possível observar o movimento de rotação do eixo que compunha a própria finalidade da política, passando do eixo interno para bases externas. $\mathrm{O}$ movimento delineava a preocupação em atendimento às políticas regionais, que pressupunham que, com a qualidade acreditada ao curso, o seu reconhecimento seria automático entre os países do bloco.

Nesse contexto, observa-se um conjunto de medidas normativas no Brasil que vão culminar com a aprovação da Resolução nº. 3/2016 e a criação da Plataforma Carolina Bori, pelo poder Executivo, além da tramitação do PL nº. 7841/2014, junto ao Poder Legislativo, com similaridades de decisões e conceitos, como o reconhecimento simplificado para os cursos acreditados pelo Arcu-Sul, que, por sua vez, vão apresentar as tendências acordadas pelos representantes brasileiros no âmbito do Mercosul, conforme pode ser observado pelo conteúdo das atas do seu GT-RT.

Essas evidências permitem inferir que a política regional está influenciando a política nacional de revalidação de títulos, que vem se apoiando no poder indutor da avaliação de cursos (acreditação) como mecanismo de gerar qualidade.

Por outro lado, notou-se pouca influência do Brasil no processo de definição das políticas regionais de avaliação, que embora sinalizem por possibilidades para o $2^{\circ}$ ciclo do Arcu-Sul de adoção de avaliação de rendimento, a exemplo da concepção brasileira de qualidade, nada foi implantado até o momento. $\mathrm{O}$ foco esteve em buscar o reconhecimento das instituições cujos cursos tenham sido acreditados, sobre o qual as instituições universitárias do Brasil tinham resistência. 
Sem dúvida, a influência da política regional sob a política de revalidação de cursos está eivada de interesses comerciais entre os países do bloco, quando se observa que o crescente número de processos de revalidação que ocorrem no Brasil é decorrente dos próprios brasileiros que estão optando pelas instituições, sobretudo privadas, dos países que compõem o Mercosul.

Nesse sentido, quando se trata de política de revalidação de títulos pode-se afirmar que o Brasil recebeu mais influências das políticas regionais do que as influenciou, apesar de sua tradição, entre os países do bloco, em avaliar a qualidade da educação superior.

\section{REFERÊNCIAS}

BALL, Stephen J. Diretrizes políticas globais e relações políticas locais em educação. Currículo sem fronteiras, São Paulo, v, 1, n. 2, p. 99-116, jul./dez. 2001.

BRASIL. Lei n ${ }^{\circ}$ 9.394, de 20 de dezembro de 1996. Estabelece as diretrizes e bases da educação nacional. Portal da Subchefia de Assuntos Jurídicos da Casa Civil da Presidência da República. Brasília, 1996.

BRASIL. Conselho Nacional de Educação. Resolução CNE/CES nº. 1, de 29 de janeiro de 2002. Brasília: Diário Oficial da União, Seção 1, p. 11, fev. 2002.

BRASIL. Decreto no $\mathbf{0} .518$, de 23 de agosto de 2005. Portal da Subchefia de Assuntos Jurídicos da Casa Civil da Presidência da República. Brasília, 2005.

BRASIL. Conselho Nacional de Educação. Resolução CNE/CES nº. 8, de 04 de outubro de 2007. Brasília: Diário Oficial da União, 2007.

BRASIL. Conselho Nacional de Educação. Resolução CNE/CES nº. 7, de 25 de setembro de 2009. Brasília: Diário Oficial da União, Seção 1, p. 30, 28 set. 2009.

BRASIL. Portaria Interministerial $n^{\circ}$. 865, de 15 de setembro de 2009. MEC/MS. Brasília: Diário Oficial da União, p. 13-19, 16 set. 2009.

BRASIL. Portaria Interministerial MEC/MS nº. 278, de 17 de março de 2011. Diário Oficial da União, Brasília, n. 53, Seção 1, p. 12.18 mar. 2011.

BRASIL, Câmara dos Deputados Federais. Projeto de Lei no. 7.841, de 2014 (Do Senado Federal), com inclusão de apensados e atualização do despacho. Atividade Legislativa. Brasília, 2014.

BRASIL. Conselho Nacional de Educação. Resolução CNE/CES nº 3 de 22 de junho de 2016. Portal do Ministério da Educação, Brasília, 2016.

BRASIL. Ministério da Educação. Portaria Normativa $n^{\circ} .22$, de 13 de dezembro de 2016. Diário Oficial da União, Brasília, Seção 1, p. 9-11, dez. 2016 b. 
CONCEIÇÃO, Jullie Cristhie da. A expansão da educação superior e os efeitos no processo de revalidação de títulos de graduação em Mato Grosso do Sul. Dourados: UFGD, 2013. Dissertação de mestrado, Universidade Federal da Grande Dourados, 2013.

DALE, Roger. Globalização e educação: demonstrando a existência de uma "Cultura Educacional Mundial Comum" ou localizando uma "Agenda Globalmente Estruturada para a Educação"?. Educação \& Sociedade, Campinas, v. 25, n. 87, p. 423-460, ago. 2004.

DALE, Roger. Os diferentes papéis, propósitos e resultados dos modelos nacionais e regionais de educação. Educação \& Sociedade, Campinas, v. 30, n. 108, p. 867-890, out. 2009.

JESSOP, Bob. A globalização e o Estado Nacional. Crítica Marxista, Campinas, n. 7, p. 945, 1998.

KRAWCZYK, Nora; SANDOVAL, Salvador Antonio Mireles. O processo de regionalização das universidades do Mercosul: um estudo exploratório de regulação supranacional e nacional. Educação e Realidade, Porto Alegre, v. 37, n. 2, p. 647-668, 2012.

\section{MARRAN, Ana Lúcia. A Construção da Política de Revalidação de Diplomas} Estrangeiros nos Poderes Legislativo e Executivo. 2018. Tese (Doutorado em Educação) Universidade Federal da Grande Dourados, Dourados, 2018.

MAZUOLLI, Valério de Oliveira. A questão do reconhecimento de títulos de mestrado e doutorado provenientes dos países do MERCOSUL. Rev. Fac. Dir. UFG, Goiânia, v. 35, n. 01, p. 216-238, jan./jun. 2011.

MEC. Ministério da Educação. Acreditação. Brasília: MEC, 2019. Disponível em: http://portal.mec.gov.br/component/tags/tag/33609. Acesso em: 16 fev. 2019.

MERCOSUL. Mercado Comum do Sul. Acordo sobre a criação e implementação de um sistema de credenciamento de cursos de graduação para o reconhecimento regional da qualidade acadêmica dos respectivos diplomas no Mercosul e Estados Associados. San Miguel de Tucumán, Mercosul Educacional, 2008. Disponível em:

http://edu.mercosur.int/arcusur/index.php/pt-br/acordo-de-criacao. Acesso em: 10 set. 2014.

MERCOSUL. Mercado Comum do Sul. Acuerdo sobre Reconocimiento de Títulos de Grado de Educación Superior en el Mercosur. Portal do Mercosul, 2018. Disponível em: https://documentos.mercosur.int/reuniones/doc/7035. Acesso em: 21 dez. 2018.

MERCOSUL. Mercado Comum do Sul. Países do Mercosul. Portal do Mercosul, 2019. Disponível em: https://www.mercosur.int/pt-br/quem-somos/paises-do-mercosul/. Acesso em: 10 jan. 2019.

REAL, Giselle Cristina Martins. Expansão e avaliação na fronteira: efeitos da política de educação superior. In: SILVA JUNIOR, João dos Reis et al. (Orgs.). Educação superior: internacionalização, mercantilização e repercussões em um campo de disputas. Belo Horizonte: Traço Fino, 2015. p. 163-182. 
ROBERTSON, Susan L. O processo de Bolonha da Europa torna-se global: modelo, mercado, mobilidade, força intelectual ou estratégia para construção do Estado?. Revista Brasileira de Educação, Rio de Janeiro, v. 14, n. 42, p. 407-422, dez. 2009.

SOUZA, Marianne Pereira de. Sistema ARCU-SUL: qualidade e regulação na confluência das políticas nacionais e regional. 2018. Tese (Doutorado em Educação) - Universidade Federal da Grande Dourados, Dourados, 2018.

VERHINE, Robert Evan; FREITAS, Antônio Alberto da Silva Monteiro. A avaliação da educação superior: modalidades e tendências no cenário internacional. Revista Ensino Superior Unicamp, v. 3, n. 7, p. 16-39, 2012.

\section{Como referenciar este artigo}

REAL, G. C. M.; MARRAN, A. L.; SOUZA, M. P. de. As influências do sistema de acreditação de cursos universitário do Mercosul no marco normativo brasileiro. Revista Ibero-Americana de Estudos em Educação, Araraquara, v. 14, n. esp. 3, p. 1655-1668, out., 2019. E-ISSN: 1982-5587. DOI: 10.21723/riaee.v14iesp.3.12739

Submetido em: 25/03/2019

Revisões requeridas: 26/04/2019

Aceito em: 30/06/2019

Publicado em: 30/08/2019 